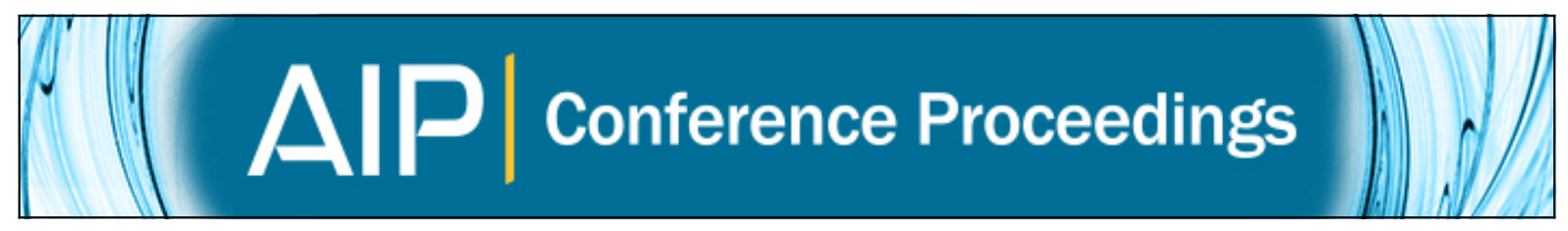

\title{
Hard x-ray nanoprobe of beamline P06 at PETRA III
}

C. G. Schroer, C. Baumbach, R. Döhrmann, S. Klare, R. Hoppe, M. Kahnt, J. Patommel, J. Reinhardt, S. Ritter, D. Samberg, M. Scholz, A. Schropp, F. Seiboth, M. Seyrich, F. Wittwer, and G. Falkenberg

Citation: AIP Conference Proceedings 1741, 030007 (2016); doi: 10.1063/1.4952830

View online: http://dx.doi.org/10.1063/1.4952830

View Table of Contents: http://scitation.aip.org/content/aip/proceeding/aipcp/1741?ver=pdfcov

Published by the AIP Publishing

\section{Articles you may be interested in}

Fast helicity switching of $x$-ray circular polarization at beamline P09 at PETRA III

AIP Conf. Proc. 1741, 030017 (2016); 10.1063/1.4952840

Time-resolved pump and probe $x$-ray absorption fine structure spectroscopy at beamline P11 at PETRA III

Rev. Sci. Instrum. 87, 053116 (2016); 10.1063/1.4948596

Development of a scanning transmission $x$-ray microscope for the beamline P04 at PETRA III DESY AIP Conf. Proc. 1696, 020041 (2016); 10.1063/1.4937535

Use of intermediate focus for grazing incidence small and wide angle x-ray scattering experiments at the beamline P03 of PETRA III, DESY

Rev. Sci. Instrum. 85, 043901 (2014); 10.1063/1.4869784

Nanoscopium: a Scanning Hard X-ray Nanoprobe Beamline at Synchrotron Soleil

AIP Conf. Proc. 1234, 395 (2010); 10.1063/1.3463222 


\title{
Hard X-Ray Nanoprobe of Beamline P06 at PETRA III
}

\author{
C. G. Schroer ${ }^{1,2, a)}$, C. Baumbach ${ }^{3}$, R. Döhrmann ${ }^{1}$, S. Klare ${ }^{4}$, R. Hoppe ${ }^{4}$, \\ M. Kahnt ${ }^{1}$, J. Patommel ${ }^{4}$, J. Reinhardt ${ }^{1}$, S. Ritter ${ }^{4}$, D. Samberg ${ }^{4}$, M. Scholz ${ }^{1}$, \\ A. Schropp ${ }^{1}$, F. Seiboth ${ }^{4}$, M. Seyrich ${ }^{1}$, F. Wittwer ${ }^{1}$ and G. Falkenberg ${ }^{1}$ \\ ${ }^{1}$ Deutsches Elektronen-Synchrotron DESY, Notkestr. 85, D-22607 Hamburg, Germany. \\ ${ }^{2}$ Department Physik, Universität Hamburg, Luruper Chaussee 149, D-22761 Hamburg, Germany. \\ ${ }^{3}$ Institute of Optics and Photonics of Condensed Matter, Technische Universität Chemnitz, D-09126 Chemnitz, \\ Germany. \\ ${ }^{4}$ Institut für Strukturphysik, Technische Universität Dresden, D-01062 Dresden, Germany. \\ a)Corresponding author: christian.schroer@desy.de
}

\begin{abstract}
The hard x-ray scanning microscope at beamline P06 of PETRA III at DESY in Hamburg serves a large user community, from physics, chemistry, and nanotechnology to the bio-medical, materials, environmental, and geosciences. It has been in user operation since 2012, and is mainly based on nanofocusing refractive x-ray lenses. Using refractive optics, nearly gaussian-limited nanobeams in the range from 50 to $100 \mathrm{~nm}$ can be generated in the hard x-ray energy range from 8 to $30 \mathrm{keV}$. The degree of coherence can be traded off against the flux in the nanobeam by a two-stage focusing scheme. We give a brief overview on published results from this instrument and describe its most important components and parameters.
\end{abstract}

\section{INTRODUCTION \& OVERVIEW}

The nanoprobe station of beamline P06 at PETRA III at DESY in Hamburg, Germany, is a hard x-ray scanning microscope designed for a broad range of applications in physics, chemistry, bio-medicine, the materials, geo-, and environmental sciences, and nanotechnology. It was designed and built in a collaboration between TU Dresden and DESY and funded within the programme "Verbundforschung" of the German Ministry of Education and Research $(\mathrm{BMBF})[1]$. It is based on nanofocusing refractive $\mathrm{x}$-ray lenses (NFLs) $[2,3,4]$ and is usually operated in the hard $\mathrm{x}$-ray range between 8 and $30 \mathrm{keV}$. Several x-ray analytical techniques are available, such as x-ray fluorescence, diffraction/scattering, and absorption spectroscopy, giving elemental, structural, and chemical contrast. In addition, tomographic scanning modes are routinely possible. In a high-coherence mode, the instrument is well suited for coherent diffraction imaging schemes, such as ptychography [5], reaching highest spatial resolution (below $10 \mathrm{~nm}$ ) and sensitivity in the hard $\mathrm{x}$-ray range. Combined with resonant scattering, ptychography can provide high-resolution images with chemical contrast [6], and in tomographic scanning mode, the three-dimensional structure (complex refractive index) of a sample can be reconstructed. This was recently demonstrated by imaging a sample of an organic tandem solar cell in three dimensions [7].

Besides being a powerful microscopy technique, ptychography is also ideal for characterizing coherent nanobeams. Many experiments at the nanoprobe at P06 have been carried out, characterizing nanofocusing refractive x-ray lenses (NFLs) [8], multilayer Laue lenses (MLL) [9, 10], Fresnel zone plates [11] and kinoform diffractive lenses [12], adiabatically focusing lenses (AFLs) [13], and refractive lamellar lenses (RLLs) [14]. The wave field around the focus can be faithfully reconstructed [15], e. g., following in detail the evolution of phase vortices along the caustic of the nanobeam [16].

In the following, we give a short description of the scanning microscope at beamline P06. It is intended to help experimentalists to prepare their experiments at this instrument. The layout of the beamline and the geometry of the scanner are shown in Fig. 1 and 2, respectively. A list of the most important components and parameters of the beamline and the nanoprobe is given in Table 1. 
a) Sector 4

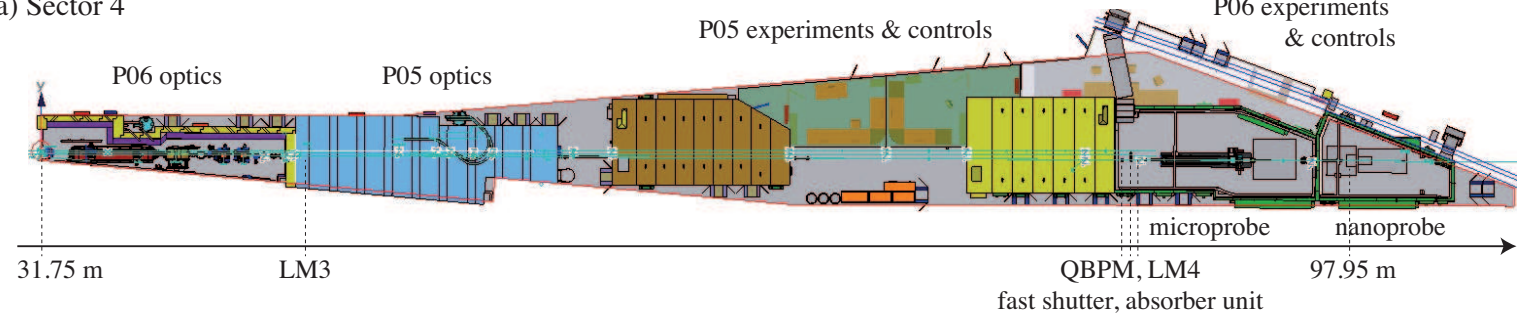

b) P06 optics

ML mono

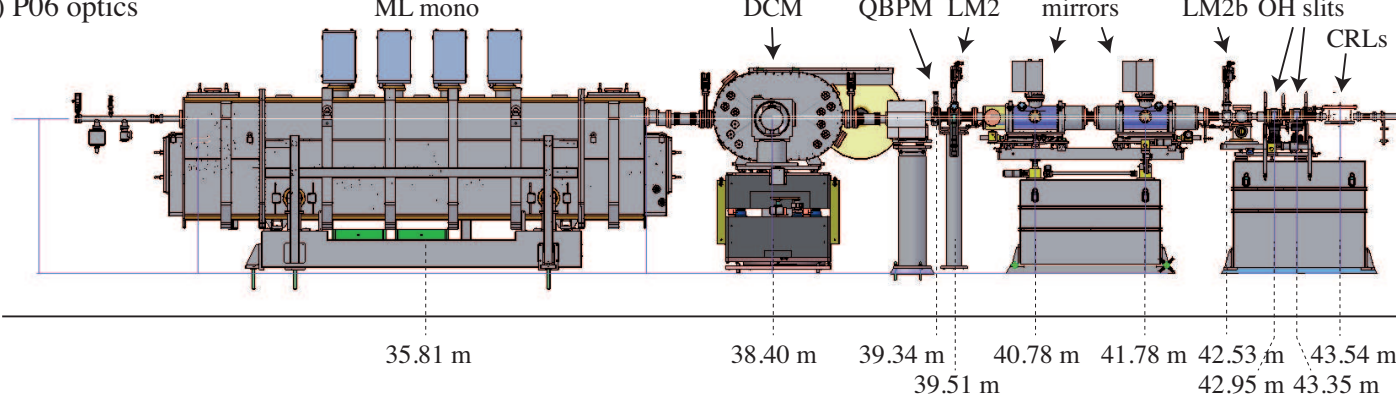

FIGURE 1. a) Schematic layout of sector 4 at PETRA III, comprising beamlines P05 and P06. The optical components of beamline P06 are shown in b). All distances are measured from the center of the insertion device.

\section{HARD X-RAY SCANNING MICROSCOPE}

The hard x-ray nanoprobe is part of beamline P06 in sector 4 of the Max-von-Laue experimental hall at PETRA III [Fig. 1a)]. A 2-m U32 spectroscopy undulator [17] $\left(\lambda_{U}=31.4 \mathrm{~mm}, K_{\max }=2.7\right)$ serves as source in this low- $\beta$ section. With an rms source size of $40 \times 6.1 \mu \mathrm{m}^{2}$ it generates a beam with a divergence of $31 \times 4.0 \mu \mathrm{rad}^{2}(E=10 \mathrm{keV})$. High-power slits define the beam entering the optics hutch: a first slit PS1 confines the beam vertically and the PS2 slits define the beam size in horizontal and vertical direction before it enters the optics hutch. The beam is monochromatized either by a multilayer monochromator (not fully commissioned, yet) or a crystal monochromator, both located in the optics hutch [Fig. 1b)]. The double crystal monochromator (DCM) has a fixed exit double-crystal (Si 111, energy range: $3-50 \mathrm{keV}$ ) and a high-stability channel-cut crystal option (Si 111, energy range: $6-18 \mathrm{keV}$ ). Two horizontally deflecting flat mirrors serve as low-pass filters for higher-harmonic rejection [Fig. 1b)]. They have reflective coatings made of $\mathrm{Si}, \mathrm{Cr}$, and $\mathrm{Pt}$ and cover a cut-off energy range from 6 to $30 \mathrm{keV} .^{1} \mathrm{~A}$ slit system $(\mathrm{OH}$ slits) located at approx. $43 \mathrm{~m}$ from the source [cf. Fig. 1b)] defines the beam transported to the experimental hutches. An integral part of the x-ray scanning microscope are rotationally parabolic compound refractive lenses (CRLs) made of beryllium [18], located at $43.54 \mathrm{~m}$ from the source. The focal length of the lens system can be adapted to the experimental needs selecting a combination of lenses from a set of 6 lens stacks $(0: N=1, R=500 \mu \mathrm{m} ; 1: N=1$, $R=300 \mu \mathrm{m} ; 2: N=1, R=200 \mu \mathrm{m} ; 3: N=2, R=200 \mu \mathrm{m} ; 4: N=1, R=50 \mu \mathrm{m} ; 5: N=2, R=50 \mu \mathrm{m}$, cf. [18] for a detailed description of the lens parameters). It allows one to trade-off coherence properties of the beam with the intensity falling onto the entrance slits of the scanning microscope. The fast shutter, controlling exposure times during experiments, is located in the microprobe hutch at $87.39 \mathrm{~m}$ from the source together with an absorber unit containing a set of aluminum foils (thickness: $5-2000 \mu \mathrm{m}$ ), which allow to attenuate the beam. Two quadrant beam position monitors (QBPMs, cf. Fig. 1) are used to determine and control the position and direction of the monochromatic beam. The beam can be observed with retractable screens (LM2, LM2b, LM3, LM4, cf. Fig. 1) along the beamline during alignment. Just in front of the scanner unit, an ionization chamber is installed to measure the $\mathrm{x}$-ray intensity entering the nanoprobe hutch.

The scanner unit of the nanoprobe is located in the last experimental hutch at about $98 \mathrm{~m}$ from the source [Fig. 1a), Fig. 2a)]. A detailed schematic view of the scanner and optics unit is shown in Figure 2. The aperture of the nanofocusing optics is defined by a pair of high-precision polished slits. The flux behind these slits is monitored by a trans-

\footnotetext{
${ }^{1}$ At a reflection angle of $2.5 \mathrm{mrad}$, the cut-off energies are 12,20 , and $30 \mathrm{keV}$, respectively. $6 \mathrm{keV}$ cut-off energy is reached for 6 mrad on Si.
} 

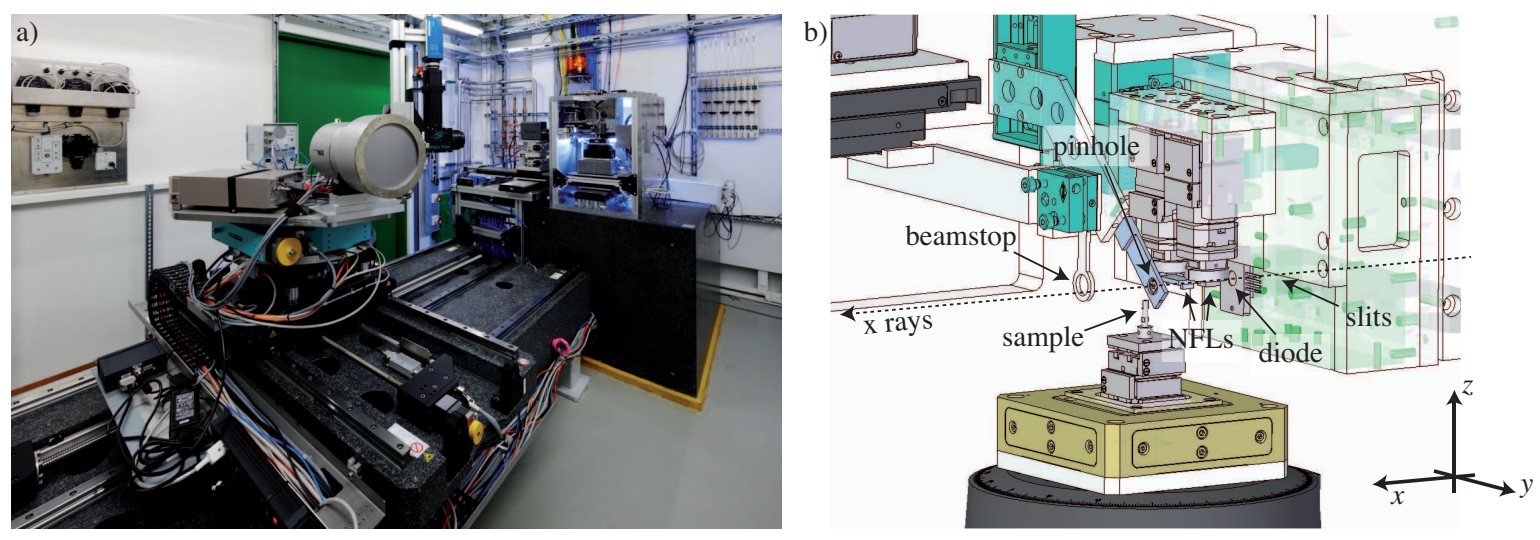

FIGURE 2. a) Photograph of the nanoprobe setup. b) Drawing of the optics and scanner unit of the nanoprobe.

TABLE 1. Hard x-ray scanning microscope (nanoprobe) at P06 of PETRA III at DESY: main components along the beamline (left) and of the instrument (right).

\begin{tabular}{|c|c|c|c|c|c|}
\hline $\begin{array}{c}\text { Beamline } \\
\text { Component }\end{array}$ & Fig. & $\begin{array}{c}\text { Postion }^{*} \\
{[\mathrm{~m}]}\end{array}$ & $\begin{array}{l}\text { Nanoprobe } \\
\text { Component }\end{array}$ & Fig. & $\begin{array}{c}\text { Postion }^{\dagger} \\
{[\mathrm{mm}]}\end{array}$ \\
\hline spectroscopy undulator U32 & & 0.00 & entrance slits & $2 \mathrm{~b})$ & 0.00 \\
\hline vertical high-power slit PS1 & & 18.91 & transmission diode & $2 b)$ & 27.0 \\
\hline high-power slits PS2 & & 26.69 & nanofocusing lens: & & \\
\hline multilayer monochromator MLM & 1b) & 35.81 & vertical & $2 b)$ & $53.0 \pm 2.5^{\ddagger}$ \\
\hline Si double crystal \& channel-cut & 1b) & 38.40 & horizontal & $2 b)$ & $66.0^{\ddagger}$ \\
\hline monochromator DCM & & & shielding & not shown & $68.0^{\S}$ \\
\hline beam position monitor QBPM mono & 1b) & 39.34 & pinhole & 2b) & $76 \pm 5$ \\
\hline retractable screen LM2 & 1b) & 39.51 & sample & 2b) & $76+75$ \\
\hline \multirow[t]{2}{*}{ flat mirrors (horiz. deflecting) } & 1b) & 40.78 & beamstop & $2 b)$ & $96 \pm 26$ \\
\hline & 1b) & 41.78 & manually adjustable up to & & $130 \pm 26$ \\
\hline retractable screen LM $2 b$ & 1b) & 42.53 & detector stage: & & \\
\hline \multirow[t]{2}{*}{ slits $\mathrm{OH}$} & 1b) & 42.95 & travel range $x$ & & 2000 \\
\hline & 1b) & 43.35 & travel range $y$ & & 1000 \\
\hline refractive $\mathrm{x}$-ray lenses CRLs & 1b) & 43.54 & travel range $z$ & & 100 \\
\hline retractable screen LM3 & 1a) & 44.66 & rotation (vertical axis) & & $360^{\circ}$ \\
\hline retractable screen LM4 & 1a) & 86.66 & fluorescence detector: & not shown & \\
\hline beam position monitor QBPM micro & 1a) & 86.83 & along optical axis $x$ & & $76+75$ \\
\hline fast shutter & 1a) & 87.39 & distance to sample $y$ & & $0.0-150$ \\
\hline absorber unit & 1a) & 87.75 & vertical position $z$ & & \pm 20 \\
\hline scanner unit entrance slits & 1a), 2b) & 97.95 & angular position & & $90^{\circ}-100^{\circ}$ II \\
\hline
\end{tabular}

mission diode. Two optics, usually nanofocusing refractive x-ray lenses, can be mounted in crossed geometry on two independent stages (attocube), each with 5 degrees of freedom. The vertically focusing lens can be adjusted in three translations and two rotations around the $y$ and $z$ axis [cf. Fig. 2b)]. The horizontally focusing optics have two translational $(y, z)$ and three rotational degrees of freedom. Scattering from the lenses is shielded by a pinhole, and a clean, nearly gaussian nanobeam is delivered to the sample position. Depending on the degree of coherence, i. e., the settings of the prefocusing CRLs, nanobeams with a flux between $10^{7}$ and $3 \cdot 10^{9} \mathrm{ph} / \mathrm{s}$ can be generated. Diffraction limited focus sizes (full width at half maximum) depend on the x-ray energy: $10 \mathrm{keV}: 100 \times 120 \mathrm{~nm}^{2}, 15 \mathrm{keV}: 80 \times 90 \mathrm{~nm}^{2}$, $20 \mathrm{keV}: 50 \times 60 \mathrm{~nm}^{2}(\mathrm{H} \times \mathrm{V})$. Lower $\mathrm{x}$-ray energies are accessible using Fresnel zone plates. 
Typical working distances for the sample range between 2 and $30 \mathrm{~mm}$. The sample can be finely scanned in three translations and one rotation. It is usually mounted on a pin ( $3 \mathrm{~mm}$ diameter, $20 \mathrm{~mm} \pm 5 \mathrm{~mm}$ length to the sample) and can laterally extend over several millimeters. The thickness of the sample should not exceed the depth of focus that lies in the range of $100 \mu \mathrm{m}$. This is also true for the sample width in case of tomography. The sample can be mounted on a small goniometer to align it for nano-diffraction, and custom sample environments can be accommodated in collaboration with the beamline staff. A Vortex-EM Si-drift-diode detector can track fluorescence radiation, while the (coherently) scattered $x$ rays can be detected by either a Pilatus 300k (Dectris) or a mar165 (rayonix) in the small- or wide-angle regime (cf. Tab. 1 for detector positioning options). Alternatively, a calibrated PIN diode is available to measure the transmitted radiation behind the sample, and a high-resolution x-ray camera (Optique Peter, PCO) can be used for full-field imaging in the direct beam. A visible-light microscope is available for sample alignment.

With this instrument, a large variety of experiments has been realized, covering approximately one third of the beamtime at beamline P06. The scanner and optics unit is currently being redesigned to improve stability and include interferometric control of the relevant degrees of freedom.

\section{ACKNOWLEDGMENTS}

This work is supported by the German Ministry of Education and Research (BMBF) under grant number 05K13OD4 and by VH-VI-403 of the Impuls- und Vernetzungsfonds (IVF) of the Helmholtz Association of German Research Centres.

\section{REFERENCES}

[1] C. G. Schroer, P. Boye, J. M. Feldkamp, J. Patommel, D. Samberg, A. Schropp, A. Schwab, S. Stephan, G. Falkenberg, G. Wellenreuther, and N. Reimers, Nucl. Instrum. Meth. A 616, 93-97 (2010).

[2] C. G. Schroer, M. Kuhlmann, U. T. Hunger, T. F. Günzler, O. Kurapova, S. Feste, F. Frehse, B. Lengeler, M. Drakopoulos, A. Somogyi, A. S. Simionovici, A. Snigirev, I. Snigireva, C. Schug, and W. H. Schröder, Appl. Phys. Lett. 82, 1485-1487 (2003).

[3] C. G. Schroer, O. Kurapova, J. Patommel, P. Boye, J. Feldkamp, B. Lengeler, M. Burghammer, C. Riekel, L. Vincze, A. van der Hart, and M. Küchler, Appl. Phys. Lett. 87, p. 124103 (2005).

[4] C. G. Schroer, S. Hönig, A. Goldschmidt, R. Hoppe, J. Patommel, D. Samberg, A. Schropp, F. Seiboth, S. Stephan, S. Schöder, M. Burghammer, M. Denecke, G. Wellenreuther, and G. Falkenberg, Advances in Computational Methods for X-Ray Optics II, Proc. SPIE 8141, p. 814103 (2011).

[5] A. Schropp, R. Hoppe, J. Patommel, D. Samberg, F. Seiboth, S. Stephan, G. Wellenreuther, G. Falkenberg, and C. G. Schroer, Appl. Phys. Lett. 100, p. 253112 (2012).

[6] R. Hoppe, J. Reinhardt, G. Hofmann, J. Patommel, J.-D. Grunwaldt, C. D. Damsgaard, G. Wellenreuther, G. Falkenberg, and C. G. Schroer, Appl. Phys. Lett. 102, p. 203104 (2013).

[7] H. F. Dam, T. R. Andersen, E. B. L. Pedersen, K. T. S. Thydén, M. Helgesen, J. C. Carlé, P. S. Jørgensen, J. Reinhardt, R. R. Søndergaard, M. Jørgensen, E. Bundgaard, F. C. Krebs, and J. W. Andreasen, Advanced Energy Materials 1400736 (2014).

[8] C. G. Schroer, F.-E. Brack, R. Brendler, S. Hönig, R. Hoppe, J. Patommel, S. Ritter, M. Scholz, A. Schropp, F. Seiboth, D. Nilsson, J. Rahomäki, F. Uhlén, U. Vogt, J. Reinhardt, and G. Falkenberg, Proc. SPIE 8848, p. 884807 (2013)

[9] S. Braun, A. Kubec, M. Menzel, S. Niese, P. Krüger, F. Seiboth, J. Patommel, and C. Schroer, J. Phys. Conf. Ser. 425, p. 052019 (2012).

[10] A. Kubec, S. Braun, S. Niese, P. Krüger, J. Patommel, M. Hecker, A. Leson, and C. G. Schroer, J. Synchrotron Rad. 21, 1122-1127 (2014).

[11] F. Uhlén, D. Nilsson, J. Rahomäki, L. Belova, C. G. Schroer, F. Seiboth, A. Holmberg, H. M. Hertz, and U. Vogt, Microelectronic Engineering 116, 40-43 (2014).

[12] P. Karvinen, D. Grolimund, M. Willimann, B. Meyer, M. Birri, C. Borca, J. Patommel, G. Wellenreuther, G. Falkenberg, M. Guizar-Sicairos, A. Menzel, and C. David, Opt. Express 22, 16676-16685 (2014).

[13] C. G. Schroer and B. Lengeler, Phys. Rev. Lett. 94, p. 054802 (2005).

[14] F. Seiboth, M. Scholz, J. Patommel, R. Hoppe, F. Wittwer, J. Reinhardt, J. Seidel, M. Knaut, A. Jahn, K. Richter, J. W. Bartha, G. Falkenberg, and C. G. Schroer, Appl. Phys. Lett. 105, p. 131110 (2014). 
[15] S. Hönig, R. Hoppe, J. Patommel, A. Schropp, S. Stephan, S. Schöder, M. Burghammer, and C. G. Schroer, Opt. Express 19, 16325-16329 (2011).

[16] D. Dzhigaev, U. Lorenz, R. P. Kurta, F. Seiboth, T. Stankevic, S. Mickevicius, A. Singer, A. Shabelin, O. M. Yefanov, M. N. Strikhanov, G. Falkenberg, C. G. Schroer, R. Feidenhans'1, and I. A. Vartanyants, J. Phys. Conf. Ser. 499, p. 012020 (2014).

[17] M. Barthelmess, U. Englisch, J. Pflüger, A. Schöps, J. Skupin, and M. Tischer, "Status of the PETRA III insertion devices," in Proceedings of EPAC08 (2008) p. WEPC133.

[18] B. Lengeler, C. G. Schroer, M. Richwin, J. Tümmler, M. Drakopoulos, A. Snigirev, and I. Snigireva, Appl. Phys. Lett. 74, 3924-3926 (1999). 